\title{
Femur Fracture Following Medial Femoral Condyle Flap Harvest: A Case Report
}

\section{Ana Klarendić (D) \\ Tadej Dovšak}

Department of Maxillofacial and Oral Surgery, University Clinical Centre, Ljubljana, 1000, Slovenia
Correspondence: Tadej Dovšak

Tel +3864I386600

Email tadej.dovsak@gmail.com
Abstract: Medial femoral condyle (MFC) corticoperiosteal free flap is a versatile flap that has been gaining popularity in maxillofacial surgery. Its relatively consistent anatomy, ease of harvest and low morbidity of the donor site make it a viable option when a small, wellvascularised piece of corticocancellous bone is needed. So far there have been only three reports of femoral fracture following an MFC free flap harvest. We present the case of a 90year-old female patient with squamous cell carcinoma of the maxilla alveolar ridge, where a $4 \times 2 \mathrm{~cm}$ MFC free flap was used for reconstruction of the defect after ablative surgery. On the third postoperative day, while the patient was lying in bed - prior to any attempt of patient verticalization - a femur fracture occurred at the donor site, requiring a surgical fixation of the femur. This is a highly uncommon complication; however, it should be taken into consideration when operating on elderly female patients. It is thus of utmost importance to stay well below the femur shaft when harvesting an MFC free flap in such patients.

Keywords: medial femoral condyle free flap, fracture, microvascular reconstruction, complication, oral cavity cancer

\section{Introduction}

Less extensive defects of the jaws (arising from congenital deformities, trauma, oncological resection, extensive alveolar ridge atrophy or infection), which encompass bone and soft tissue and can lead to communication between oral cavity and nose or maxillary sinus, require complex reconstruction. Microvascular tissue transfer provides wellvascularized tissue at the transplantation site, enabling reliable functional and aesthetic rehabilitation. ${ }^{1}$ When considering the donor site for tissue transfer, a variety of aspects must be taken into account, namely, size and site of the defect, tissues involved, patient's age and occupation, comorbidities and the possibility of postoperative radiotherapy. ${ }^{1-3}$

Bone (and not only soft tissue) is preferably used to replace the bone defect after resection, allowing for a dental rehabilitation later on. The following free flaps are traditionally used in reconstruction of compound jaw defects: iliac crest-, fibular-, radial forearm- and scapular-free flaps. ${ }^{4,5}$ For smaller compound defects requiring a wellvascularized cancellous bone, our preferred choice is the medial femoral condyle (MFC) flap, which was first described in 1989 for osteocartilaginous reconstruction of the leg. ${ }^{6}$ It consists of periosteum, cortical, and cancellous bone, harvested from medial femoral trochlea, and is based on the descending genicular artery and vein. ${ }^{1,7}$ Together with perforator vessels, muscle tissue, tendon, and/or skin can also be used. The MFC free flap has numerous advantages: versatility, relative ease of dissection, reliable vascularity, preservation of all major arteries to the distal extremity, osteogenic potential, good 
cancellous bone quality, the possibility of a two-team approach and relatively low donor site morbidity. All of these have contributed to the increasing use of the MFC free flap in reconstructing defects of diverse sizes and designs. ${ }^{7-15}$

\section{Case Presentation}

We present the case of a 90-year-old female patient with a histologically proven squamous cell carcinoma of the alveolar ridge of the maxilla. She was living alone, still able to take care of herself. Her polymorbidity was due to aortic valve replacement, atrial fibrillation (with implanted pacemaker), a myocardial infarction, a proven bronchiectasis, and a total hip replacement. She had bone density measured 3 years prior to hospitalization, with results within normal range for her age. She was noticing changes in the maxillary mucosa for more than 6 months, experiencing pain while chewing for the last month, and her dentures could no longer fit. Tumor was extending from region 12 to 22 (Figure 1), there was no progression in the nasal cavity, but radiologically evident bone destruction. Mandible was edentulous, but teeth 13 and 12 were present in the maxilla. Computer tomography with contrast showed no metastases in the neck and a $2 \times 2 \mathrm{~cm}$ tumor of the alveolar ridge of maxilla, with bone destruction of premaxilla. Tumor was categorized as T4NO. ${ }^{16}$ Due to the bone invasion, the tumor was not suitable for radiotherapy, thus a multidisciplinary board decided on primary operative treatment despite the patient's polymorbidity and age.

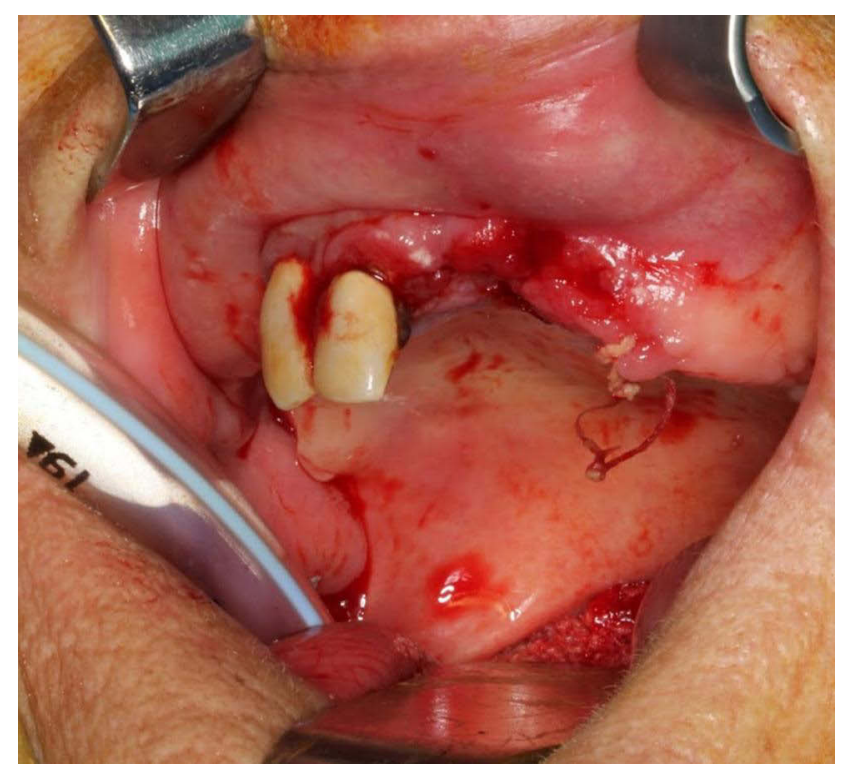

Figure I Squamous cell carcinoma on the alveolar ridge of maxilla in regions 12 to 22 .
Due to the tumor location in the premaxilla, postablation communication between oral and nasal cavity was expected, therefore a nose and upper lip support was planned. Obturator fixation was not possible due to severely resorbed maxilla, therefore we decided on microvascular reconstruction of the composite defect, despite the patient's age and comorbidity.

Even though we were aware of the possible limitations of raising the free flap in a 90-year-old female patient, we were faced with two challenges. Having removed cancer together with the premaxilla, we had to close the oronasal communication and at the same time provide support for the nose and upper lip. Since the vascular study of the lower leg showed only two patent vessels on each lower leg, fibula was not an option. It was vital to minimize the patient's time in general anesthesia and to enable her to resume normal activities as soon after surgery as possible, which called for a two-team approach. We decided on a femoral flap because it provided the needed stock of bone for nose support, a nice periosteal coverage for the epithelization, the possibility of a two-team approach and its relatively low donor site morbidity.

The tumor was completely resected (Figures 2 and 3 ) and intraoperative frozen sections tested negative. An MFC free flap was raised on a descending genicular artery from the left leg with bone graft of $4 \times 2 \mathrm{~cm}$ and a slightly larger periosteal sheath (Figure 4). In the end, microvascular anastomoses with facial artery and vein were completed intraorally under the operating microscope. Bone was fixated to the maxilla using

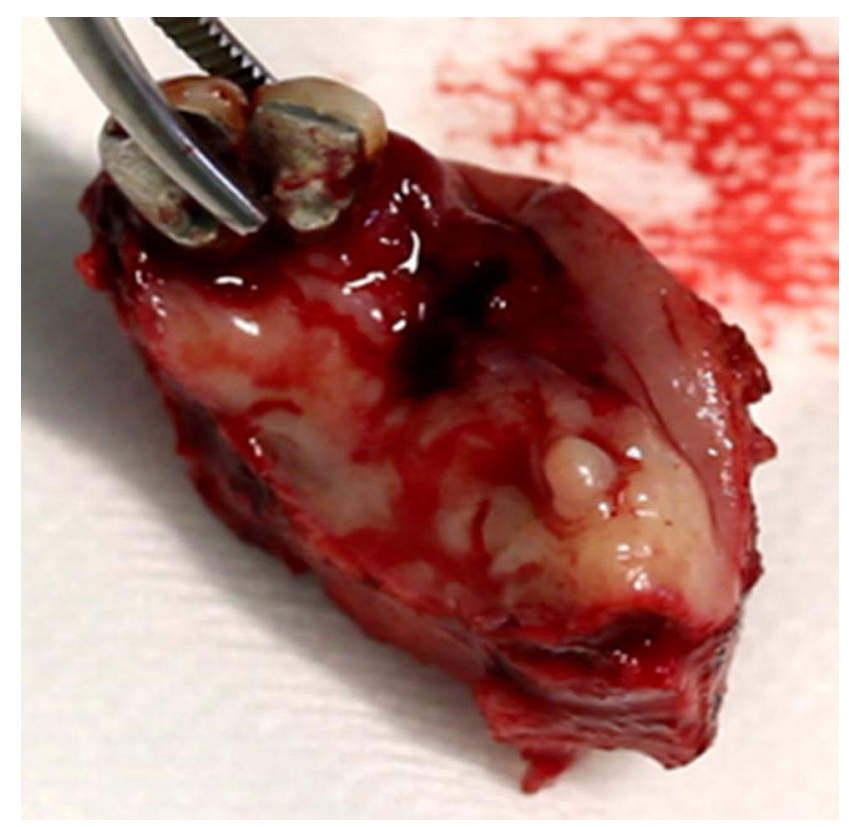

Figure 2 Resected specimen of tumor together with the whole premaxilla. 


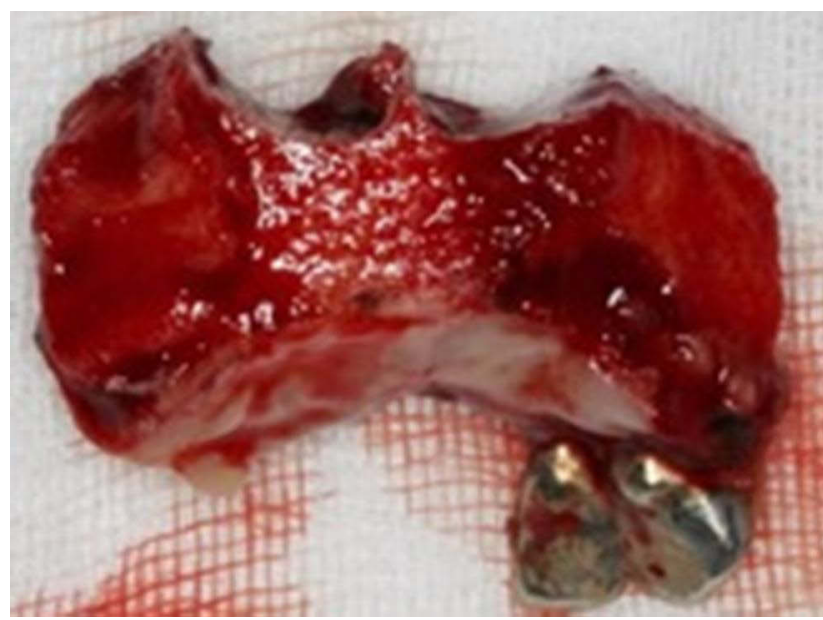

Figure 3 Posterior view of the resected specimen.

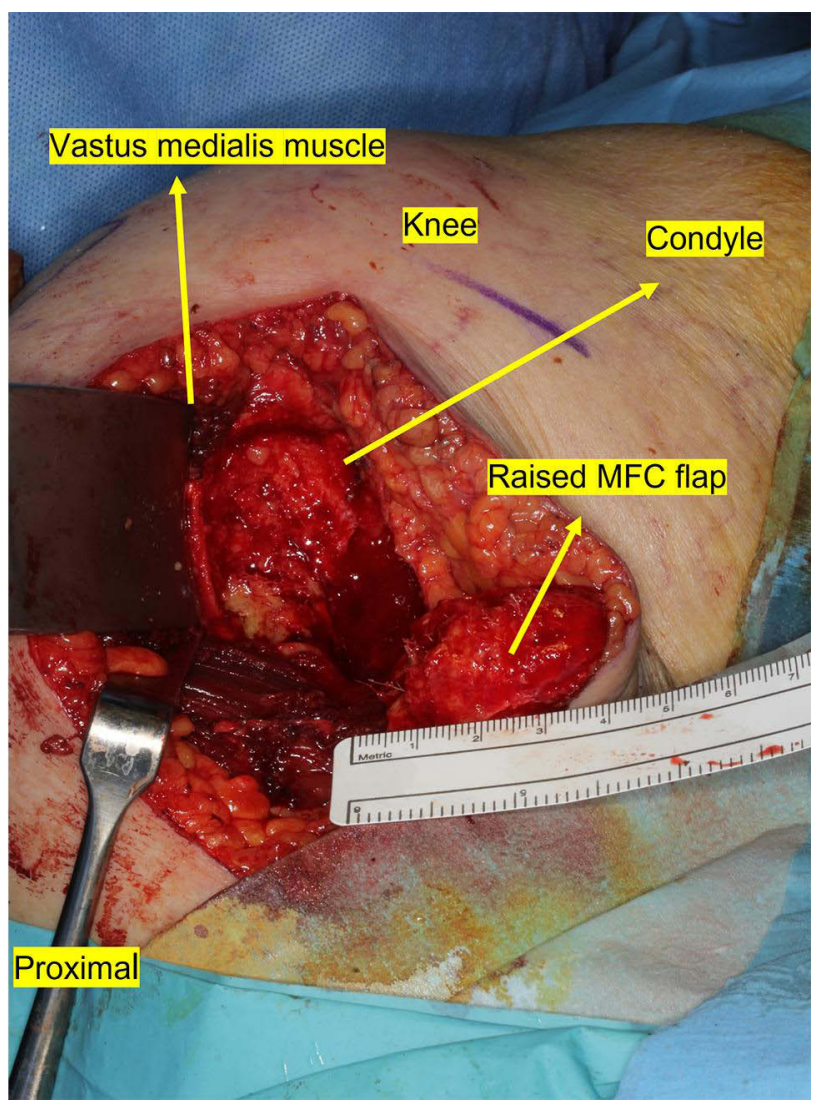

Figure $44 \times 2 \times \mathrm{I} \mathrm{cm} \mathrm{MFC} \mathrm{flap} \mathrm{raised} \mathrm{from} \mathrm{the} \mathrm{left} \mathrm{femoral} \mathrm{condyle.}$

DePuy Synthes ${ }^{\circledR} 2.0$ mini titanium plates. Nasogastric tube was placed, the patient was intubated and sedated for the first 24 hours. We monitored the flap clinically and with the handheld Doppler device.

Active physiotherapy in bed was introduced on postoperative day one, plain x-rays of the femur were taken on day two (Figure 5), and patient verticalization was

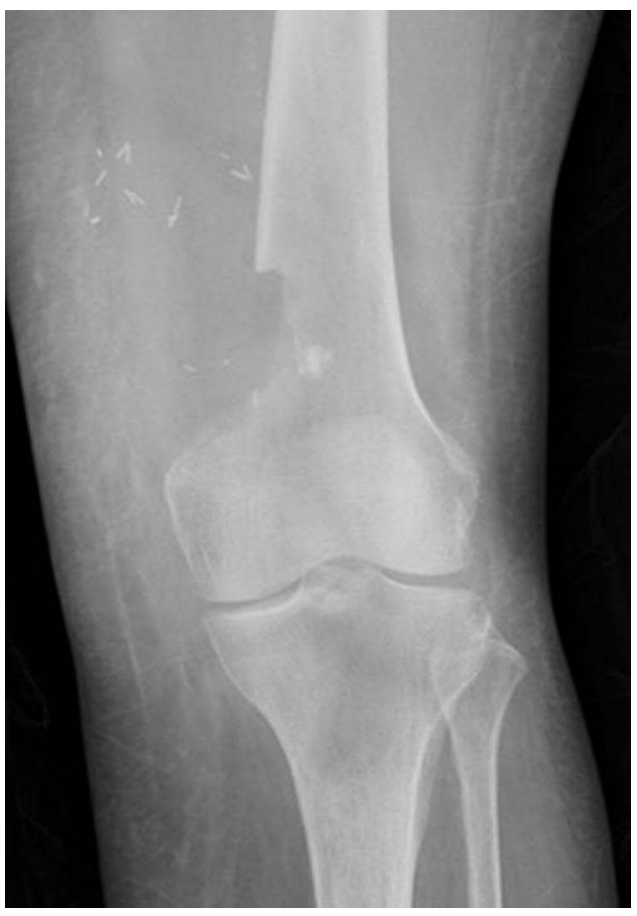

Figure 5 Plain radiograph of the femur on the second postoperative day with evident osteopenia.

planned for day three. However, this had to be postponed as the patient reported hearing a loud crack while turning over in bed, and a sensation of pain around the left knee area, which was aggravated by each attempt at movement. X-ray of the region showed a fractured femur just above the level of MFC harvesting (Figure 6). The patient was transferred to the traumatology department, where the fracture was treated with intramedullary nail fixation (Figure 7).

Final histopathology report stated grade II squamous cell carcinoma grossly invading the bone and measuring $15 \times 10 \mathrm{~mm}$. The depth of invasion was $8 \mathrm{~mm}$, with neither perineural nor lymphovascular invasion. Resection margins were free of tumor cells. At the postoperative tumor board meeting, the tumor was staged as pT4Nx, and postoperative radiotherapy of the tumor bed was indicated. Rehabilitation was slow and radiotherapy began 8 weeks after surgery. Figure 8 shows the patient before the beginning of radiotherapy, when epithelization of periosteum was almost completed. She received 33 fractions of $2 \mathrm{~Gy}$, with a cumulative dose of 66 Gy. Figure 9 shows the patient three months after radiotherapy. The patient never regained her preoperative walking ability. She continued to use a wheelchair but was nevertheless able to walk for a short distance. There was no sign of tumor recurrence at the follow-up check-ups. The patient died 2 years later of viral pneumonia. 


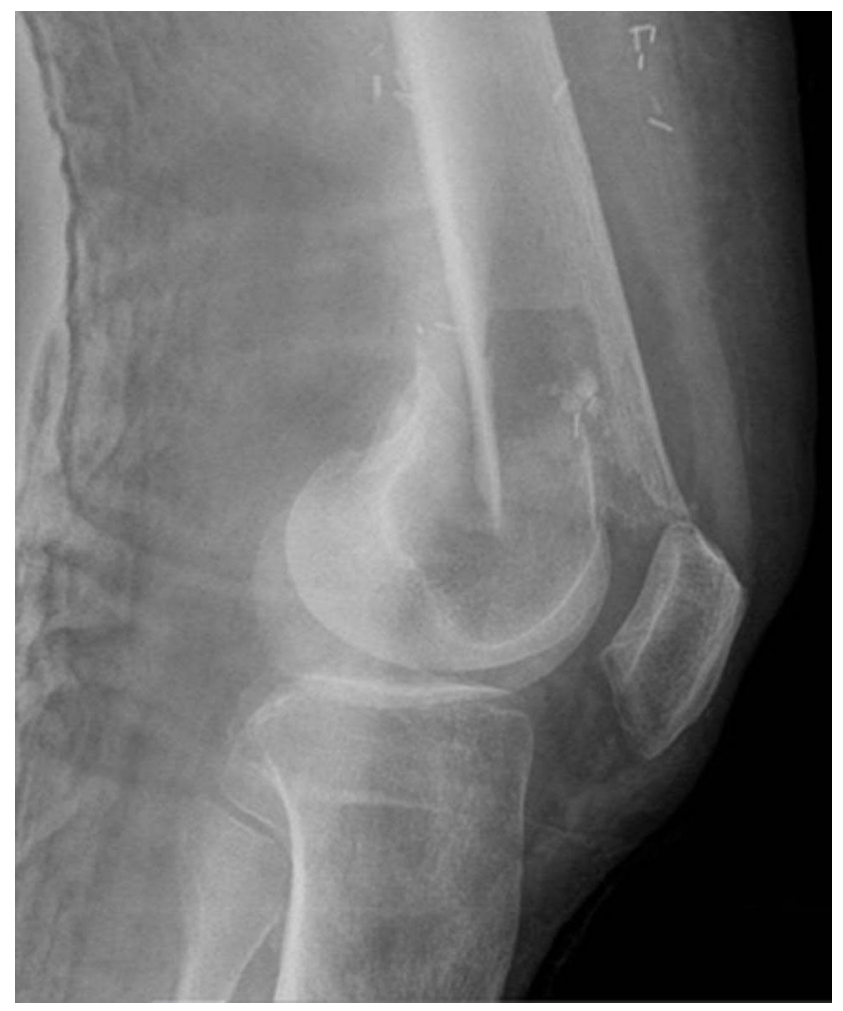

Figure 6 Plain radiograph of the fractured femur on the third postoperative day.

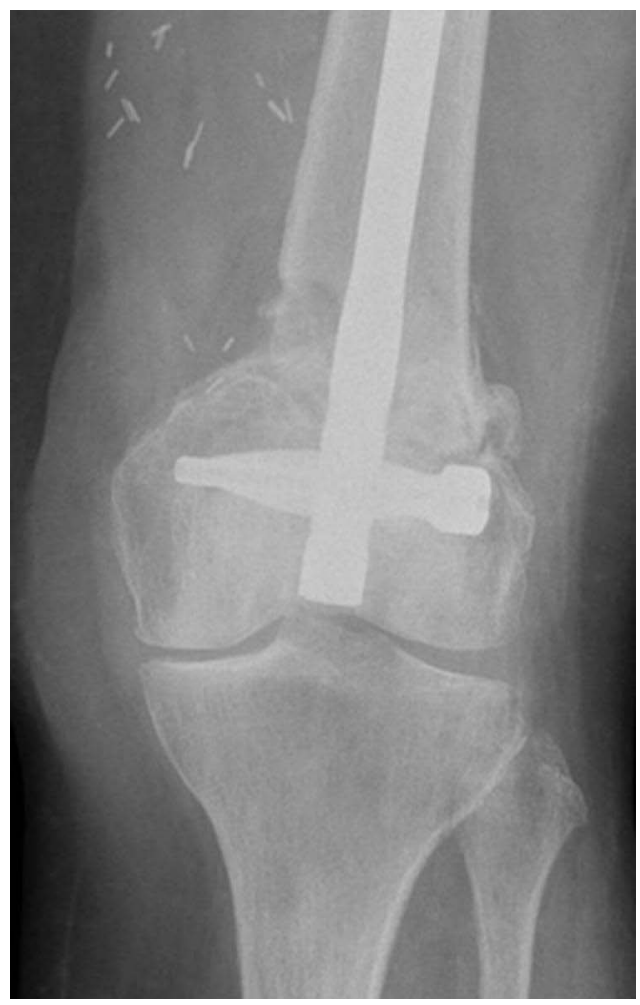

Figure 7 Patient's femur fixed with medullary nail 6 months after fixation.

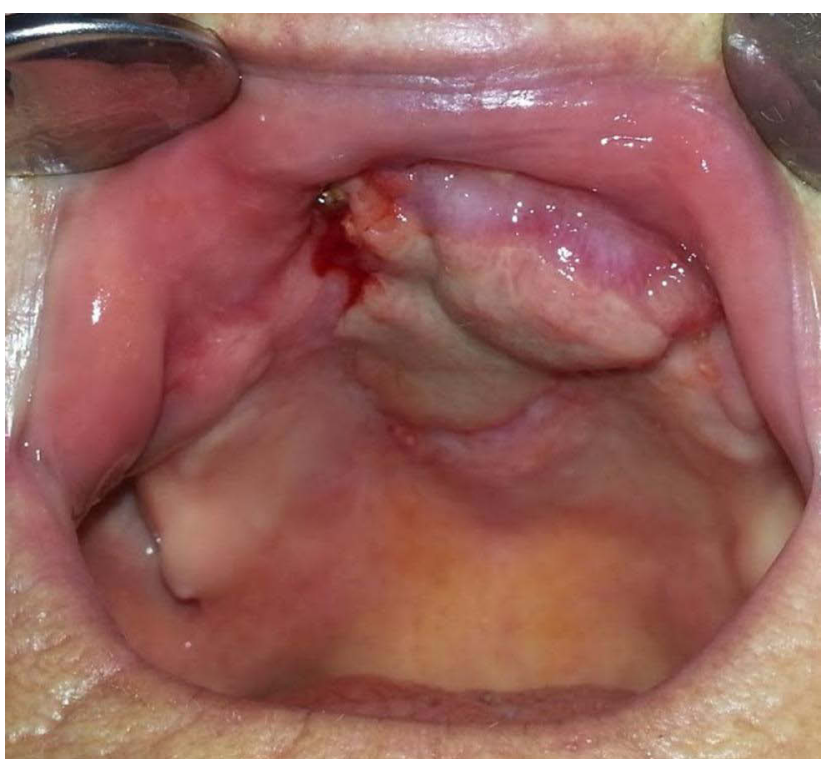

Figure 8 Periosteum of the flap almost completely covered with mucosa.

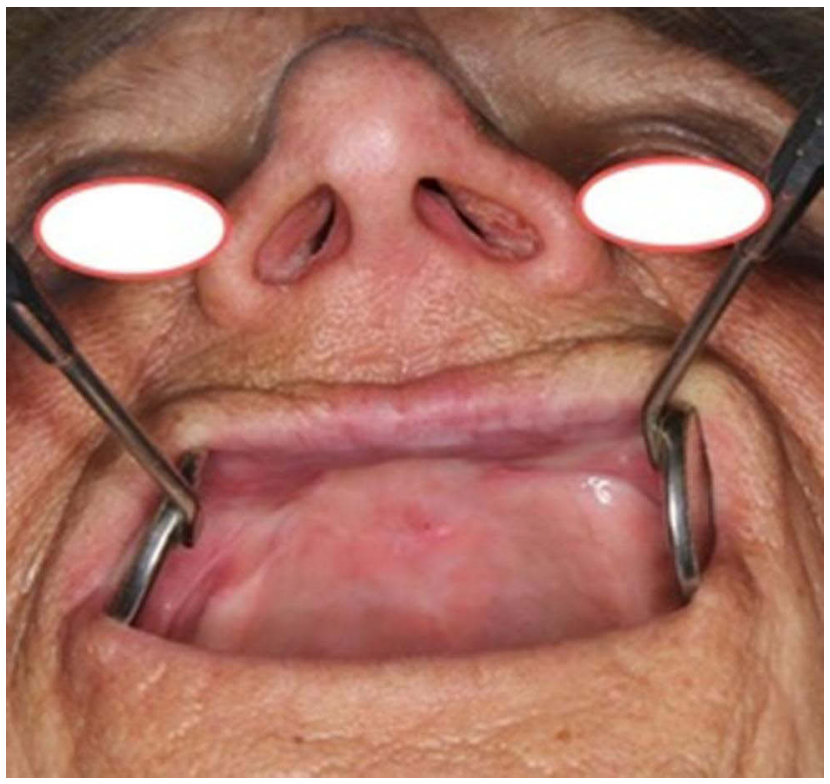

Figure 9 Patient on follow-up three months after radiotherapy with good lip and nose support.

\section{Discussion}

Complications occurring at the donor site after the MFC free flap harvest are rare and this case report presents one of them. Some of the most frequently reported complications are nerve-related, such as paresthesia and numbness in the saphenous nerve distribution. Seroma formation, infection and deep vein thrombosis occur less often. Limitations in physical activity due to continuous knee 
discomfort and a decreased range of motion are some of the most common difficulties patients experience after the surgery. The donor site pain should subside in a twomonth period following the procedure; however, its transition into chronic pain is also reported. ${ }^{1,13,17,18}$

Iatrogenic femur fractures following the harvest of an MFC flap are very infrequent. Biomechanical studies have demonstrated that a large MFC flap can be harvested without risking the femur fracture at the donor site in axial load application. ${ }^{11,12,19}$ An MFC flap may include entire medial surface of the condylar and supracondylar region; however, there are some variations in the literature regarding the supposed dimensional limitations of the MFC flap: 10 $13 \mathrm{~cm}$ (length), 7-8 cm (width) and $1.5 \mathrm{~cm}$ (depth). ${ }^{2,18}$ Moreover, the flap is anteriorly limited by the medial patellar facet, posteriorly by the posterior border of femur, and distally by the origin of the medial collateral ligament. ${ }^{2,10,20}$

In our case, the size of the flap was $4 \times 2 \mathrm{~cm}$, with a thickness of $1 \mathrm{~cm}$. A harvest of bone flaps smaller than 6 $\times 6 \mathrm{~cm}$ has been advised to avoid upper osteotomy in the femur shaft, which would require plating to prevent the fracture of diaphysis. In our patient, the flap was $4 \mathrm{~cm}$ long and the upper osteotomy was performed just below the femoral shaft. However, it still caused enough biomechanical weakness for the shaft to fracture.

According to studies done by Katz et al, ${ }^{19}$ the biomechanical stability of the knee is preserved even with flaps up to $24 \mathrm{~cm}$. Furthermore, Mehio et al ${ }^{13}$ reported no major complications in their series within the group of patients with flaps larger than $5 \mathrm{~cm}$ and noted that, when compared with corticoperiosteal flaps, the cortiococancellous ones showed no risk increase. In our case, the postoperative femur fracture could be linked to the proximal position of the MFC free flap harvest. In order to include as many periosteal vessel branches as possible, we raised the flap where metaphysis and femoral shaft meet. However, the fracture may also be linked to osteoporosis of the patient, which allowed for the femur fracture even when small torsion force was applied during the patient's rotation in bed.

We found only three instances of femoral fracture reported in the case repository, two of which offered more in-depth information. ${ }^{17,21,22}$ Both patients were 61 years old, one male (treated for osteomyelitis of distal radius) and one female (treated for clavicle nonunion), with no mentioned comorbidities. In both cases the femur fracture occurred after the verticalization of the patient had been completed, 2-3 weeks after the harvest of MFC flap, during walking, without a direct trauma, accompanied by sudden experience of severe knee pain. The flap dimensions were $6 \times 1 \times 1 \mathrm{~cm}$ and $5.5 \times 3.5 \mathrm{~cm}$, respectively, proving that even dimensions below $6 \mathrm{~cm}$ can lead to femoral fracture.

With a view to providing a more in-depth understanding of how the biomechanical characteristics of the femur following a bone graft harvest change in relation to the graft dimensions, a few experimental studies have been conducted. One of the studies attempted to evaluate the potential efficacy of prophylactic fixation and to prove the beneficial role of postoperative stabilization. ${ }^{5}$ Two studies evaluated changes in mechanical properties, ie, torsional and axial stability as well as structural integrity, both the consequence of a femoral flap harvest, to find that femur deformation during load increases and stiffness decreases proportionally to the size of the harvested graft. In one of these studies focusing on the donor site response to torsional forces, an increasingly large segment of MFC flap were harvested and the ensuing biomechanical evaluations showed that the flap harvest of any size reduces donor site failure torque; however, no decline in osseous stability was observed regardless of the flap's dimensions. Another conclusion of this study was that the flap harvests exceeding $7 \mathrm{~cm}$ show higher occurrence of iatrogenic fractures, warranting caution with postoperative torsional loading of the knee. $^{11,19}$

The correlation between osteoporosis and MFC flap harvest has also been addressed in some studies. In patients treated for head and neck cancer, osteoporosis is not a rare comorbidity. Bone fragility results from osteoporotic changes influencing mechanical and structural properties of skeletal tissue, such as reduced ability to withstand deformation and adapt to repetitive load. When a flap is harvested from such a bone, the deficiency at the donor site aggravates mechanical properties, which could result in bone fracture. ${ }^{23}$

\section{Conclusion}

Small compound defects of the anterior maxilla present a rehabilitation problem due to the following reasons: the oronasal communication and the loss of nasal and lip support, the inability to satisfactorily fixate the potential obturator prosthesis, and remote vessels for microvascular anastomoses. Such defects are usually too small for conventional workhorse flaps in head and neck area such as fibula or iliac crest. In our department we believe that such 
defects are best reconstructed with an MFC flap with intraorally performed microvascular anastomoses. However, it is important to remember that femur fracture after MFC flap harvest is possible, even with moderate dimensions of the flap. This is the fourth case reported in the literature that we know of. Every surgical complication that might postpone or cancel postoperative radiotherapy can influence disease control and survival. Although this was not the situation in our case, the patient's preoperative range of mobility nevertheless decreased.

It is thus vital to take some precautions and stay well below the femur shaft when deciding to harvest an MFC flap in elderly (and possibly osteoporotic) female patients. Surgical treatment of oncological patients should always be planned individually, and important factors such as the patient's age, sex, and comorbidities should be considered. Microvascular reconstruction in elderly patients is feasible, but when bony reconstruction is needed, vascularity can be a challenge. In smaller, limited composite defects of bone and mucosa, the MFC flap might well be a possible solution.

Based on our and other published cases, not enough has been known about the limitations of MFC flap harvesting in elderly oncologic patients. It is thus difficult to offer specific recommendations as far as its use, indications, and contraindications are concerned, and we believe further research in this field is still required. However, we do know that the harvest of flaps reaching the femoral shaft should be avoided in such cases and, when possible, other bony flaps might be a safer solution when treating an osteoporotic patient.

\section{Statement Confirming Consent to Publish}

Patient consent to publish has been obtained.

\section{Acknowledgments}

We would like to sincerely thank Prim. Vojko Didanovič for his outstanding support during surgery and in the writing of this case report and Nina Gorenc for invaluable comments and proofreading.

\section{Funding}

The research did not receive specific funding.

\section{Disclosure}

The authors have no conflicts of interest to declare.

\section{References}

1. Haumer A, Ismail T, Lunger A, et al. From autologous flaps to engineered vascularized grafts for bone regeneration. In: Vascularization for Tissue Engineering and Regenerative Medicine. Springer International Publishing Cham; 2017:1-34.

2. Gaggl A. Other free flaps in head and neck reconstruction. In Brennan PA, editor. Maxillofacial Surgery. 3rd ed. Chapter 42. Elsevier; 2017.

3. Chang EI, Hanasono MM, Butler CE. Management of unfavorable outcomes in head and neck free flap reconstruction: experience-based lessons from the MD Anderson cancer center. Clin Plast Surg. 2016;43(4):653-667. doi:10.1016/j.cps.2016.05.001

4. Powers D, Rodriguez ED. Reconstruction of avulsive defects of the maxillofacial complex. In: Oral and Maxillofacial Trauma. Elsevier; 2013:763-789.

5. Mitchell DA, Macleod SP. Strategies for avoiding complications with vascularized bone flaps in head and neck microvascular reconstruction. Semin Plast Surg. 2008;22(3):175-185. doi:10.1055/ s-2008-1081401

6. Hertel R, Masquelet AC. The reverse flow medial knee osteoperiosteal flap for skeletal reconstruction of the leg. Description and anatomical basis. Surg Radiol Anat. 1989;11:257-262. doi:10.1007/ BF02098691

7. Doi K, Hattori Y. Vascularized bone graft from the supracondylar region of the femur. Microsurgery. 2009;29(5):379-384. doi:10.1002/ micr.20671

8. Wong VW, Higgins JP. Medial femoral condyle flap. Plast Reconstr Surg Glob Open. 2016;4(8):e834. doi:10.1097/GOX.00000 00000000815

9. Hupp JR, Ellis E III, Tucker MR. Contemporary Oral and Maxillofacial Surgery. 5th ed. Chapter 29. Elsevier; 2008.

10. Iorio ML, Masden DL, Higgins JP. The limits of medial femoral condyle corticoperiosteal flaps. $J$ Hand Surg Am. 2011;36 (10):1592-1596. doi:10.1016/j.jhsa.2011.07.015

11. Endara MR, Brown BJ, Shuck J, Bachabi M, Parks BG, Higgins JP. Torsional stability of the femur after harvest of the medial femoral condyle corticocancellous flap. J Reconstr Microsurg. 2015;31 (5):364-368. doi:10.1055/s-0035-1546420

12. Boretto JG, Altube G, Gallucci GL, Narvaez HR, De Carli P. Femoral osteonecrosis after medial femoral condyle bone graft harvest. Plast Reconstr Surg Glob Open. 2018;6(6):e1792. doi:10.1097/GOX.00 00000000001792

13. Mehio G, Morsy M, Cayci C, et al. Donor-site morbidity and functional status following medial femoral condyle flap harvest. Plast Reconstr Surg. 2018;142(5):734e-741e. doi:10.1097/PRS.0000 000000004886

14. Guzzini M, Lupariello D, Argento G, Arioli L, Ferretti A. Vascular and bone regeneration of the donor site after corticoperiosteal flap from the medial femoral condyle. HAND. 2020:155894472093029. doi: $10.1177 / 1558944720930299$

15. Guzzini M, Arioli L, Rugiero C, Rossini M, Argento G, Ferretti A. Donorsite defect of medial femoral condyle corticoperiostal flap in the treatment of lower limb infected nonunions. Handchir Mikrochir Plast Chir. 2021;53(4):376-382. doi:10.1055/a-1240-0181

16. Edge SB; American Joint Committee on Cancer, American Cancer Society. AJCC Cancer Staging Handbook: From the AJCC Cancer Staging Manual. 7th ed. New York, NY: Springer; 2010.

17. Haines M, Baba M, Stewart DA. Iatrogenic femur fracture following medial femoral condyle flap harvest. J Hand Surg Am. 2020;45 (9):885.e1-885.e3. doi:10.1016/j.jhsa.2019.12.001

18. Bakri K, Shin AY, Moran SL. The vascularized medial femoral corticoperiosteal flap for reconstruction of bony defects within the upper and lower extremities. Semin Plast Surg. 2008;22(3):228-233. doi:10.1055/s-2008-1081405 
19. Katz RD, Parks BG, Higgins JP. The axial stability of the femur after harvest of the medial femoral condyle corticocancellous flap: a biomechanical study of composite femur models. Microsurgery. 2012;32:213-218. doi:10.1002/micr.20986

20. Rao SS, Sexton CC, Higgins JP. Medial femoral condyle flap donor-site morbidity: a radiographic assessment. Plast Reconstr Surg. 2013;131(3):357e-362e. doi:10.1097/PRS.0b013e31827c6f38

21. Son JH, Giladi AM, Higgins JP. Iatrogenic femur fracture following medial femoral condyle flap harvest eventually requiring total knee arthroplasty in one patient. J Hand Surg Eur Vol. 2019;44(3):32 0-321. doi:10.1177/1753193418813687
22. Hamada Y, Hibino N, Kobayashi A. Expanding the utility of modified vascularized femoral periosteal bone-flaps: an analysis of its form and a comparison with a conventional-bone-graft. J Clin Orthop Trauma. 2014;5(1):6e17. doi:10.1016/j.jcot.2014. 01.002

23. Nokovitch L, Brantus JF, Vaz G, Deneuve S. Arguments for osteoporosis screening when free fibular flap reconstruction is being considered for head and neck patients. $\mathrm{Br} J$ Oral Maxillofac Surg. 2020;58(3):377-379. doi:10.1016/j.bjoms.20 20.02.003
Open Access Surgery

\section{Publish your work in this journal}

Open Access Surgery is an international, peer-reviewed, open access journal that focuses on all aspects of surgical procedures and interventions. Patient care around the peri-operative period and patient outcomes post-surgery are key topics for the journal. All grades of surgery from minor cosmetic interventions to major surgica procedures are covered. Novel techniques and the utilization of new

Submit your manuscript here: https://www.dovepress.com/open-access-surgery-journal

\section{Dovepress}

instruments and materials, including implants and prostheses that optimize outcomes constitute major areas of interest. The manuscript management system is completely online and includes a very quick and fair peer-review system, which is all easy to use. Visit http://www.dovepress.com/testimonials.php to read real quotes from published authors. 